\title{
Sustainable Management of Montane Forest and Landscape Tranformation Within the Oku Highlands of Cameroon
}

\author{
Godwill Tobouah Nyanchi ${ }^{1,}$,, Tassah Ivo Tawe ${ }^{1}$, Jude Kwei ${ }^{2}$ \\ ${ }^{1}$ Department of Geography, Faculty of Arts, Letters and Social Sciences (FALSH), University of Yaoundé 1, Cameroon \\ ${ }^{2}$ Department of Geography and Planning, University of Bamenda, Cameroon
}

Email address:

goddy288@yahoo.com (G. T. Nyanchi), tasswise@yahoo.co.nz (T. I. Tawe)

${ }^{*}$ Corresponding author

\section{To cite this article:}

Godwill Tobouah Nyanchi, Tassah Ivo Tawe, Jude Kwei. Sustainable Management of Montane Forest and Landscape Tranformation Within the Oku Highlands of Cameroon. Landscape Architecture and Regional Planning. Vol. 6, No. 2, 2021, pp. 25-36.

doi: 10.11648/j.larp.20210602.12

Received: May 19, 2021; Accepted: June 17, 2021; Published: June 26, 2021

\begin{abstract}
The setbacks of deforestation over the years have given light to awareness on the importance of regeneration. The benefits of forest regeneration are numerous both to the environment and man. The main objectives of this study were to assess forest regeneration dynamics and its implication on landscape projection in Oku. This study adopted both primary and secondary methods of data acquisition. This involved the administration of questionnaires, field visits, focus group discussions, observation and key informant interviews. This was practicable based on the accessibility and the potentials of the study area. In addition, satellite images of the study area were exploited to portray the rate of deforestation over the years and extent of tree planting within the area. Collected data was expected to enhance an understanding of endeavours of the local population to protect and regenerate exploited areas. The study found out that the local population are conscious, appreciative and encourage forest regeneration activities. Questionnaire exploitation revealed that $91 \%$ of the population plant trees in their farms. These trees range from soil fertilizer species, fruit trees and suitable trees for wood carving. The study equally revealed that $80 \%$ of local NGOs present within the matrix area are involved in forest regeneration. As a result of this, the cumulating local efforts of forest revival respects mitigation designed on climate change. The fact that local communities accept the canons of forest regeneration is of maximum importance in guaranteeing environmental benefits.
\end{abstract}

Keywords: Montane Forest, Regeneration, Tree Planting, Landscape Modification

\section{Introduction}

The hope for the future lies in agro forestry, where trees and food crops are grown alongside each other. Forest soils, normally rated unsuitable for crops, can be improved by growing leguminous tree species [1]. Trees have commonly formed an important part in Africa's traditional farming systems. Farmers in Oku are involved in food crops, cash crops and fruit trees cultivation. As a result, rural farmers therefore exploit the potentials of trees and shrubs on the farms. This article is basically focused on forest renewal activities gaining grounds around the Oku mountain area. The valuable contribution of fruit trees in Oku remains an additional source of food supply. Another part of the overall tree integration program is a project for the planting of fruit trees. In most farms within the study area, fruit trees are eliminated as soon as their productivity starts decreasing giving way to planting valuable and more productive species.

\section{Geographic Location, Soils and Vegetation Background}

\subsection{Geographic Location}

Oku is one of the Five Sub-Divisions that make up BuiDivision in the North West Region of the Republic of Cameroon. The study area falls within latitude $6^{0} 5^{\prime}$ and latitude $6^{\circ} 15^{\prime}$ North of the equator and longitudes $10^{\circ} 20^{\prime}$ and 
$10^{0} 40^{\prime}$ East of the Greenwich meridian. Mount Oku (3011m) is the second highest mountain in mainland West Africa. To the North, Oku shares boundary with Noni Sub-Division, to the South with Babungo in Ngoketunjia Division and to the East with Kumbo and Jakiri Sub-Division as seen in figure 1.

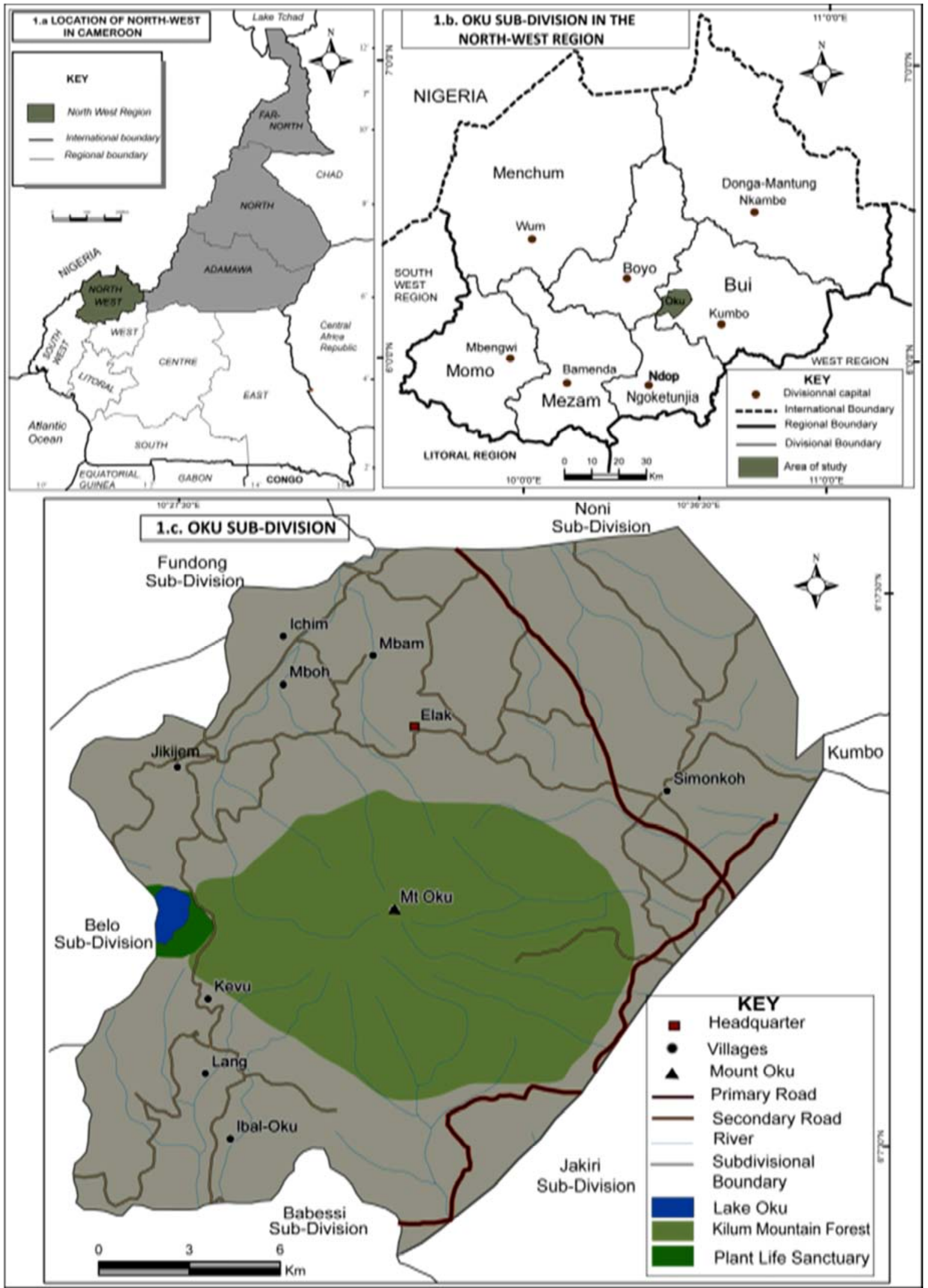

Source: Land sat, 2017

Figure 1. Location of the study site (a) the North West Region in Cameroon, (b) Bui Diviion in the North West Region (c) Oku Sub-Division. 


\subsection{Soils}

The soil types in Oku Sub-Division are heterogeneously distributed due to parent rock differences. These comprise of ancient Precambrian basement complex rocks made up of granitic soils, trachytic soils, volcanic soils and basaltic soils as seen in figure 2. High lava plateau soils are mainly found at altitudes of $1800-2520 \mathrm{~m}$. The low altitudes are covered with low lava plateau soils at altitudes of about $1400 \mathrm{~m}$ [2]. Agricultural practices largely depend on these soils for food supply. The cultivation of tree and food crops is largely dependent on the deep fine soil in Oku. This deep soil provides an anchorage where the roots can tap sufficient nutrients. There is a relationship between soil types and agricultural intensity. Agro forestry practices thrive in areas having different soil types such as the case of our study area. Widespread soil distribution with different characteristics determines the agricultural type operating within different zones.

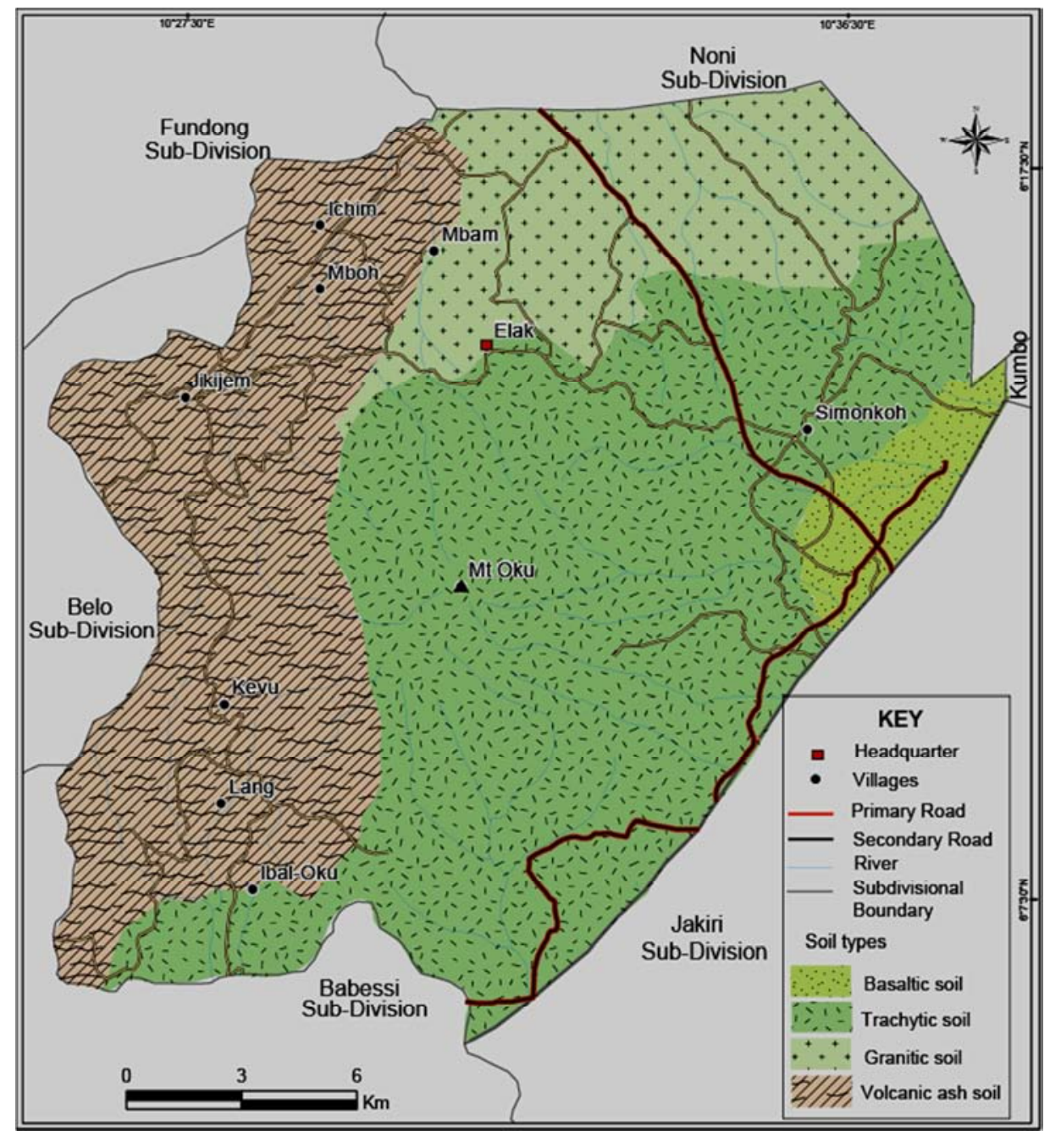

Source: Land sat 2017

Figure 2. Soil distribution map of Oku.

Forest soils in upland Oku are mostly dominated by trachytic soils. Soils here are characterised by deep profiles with high clay content. Deforested areas such as Ngashie, Keyon, Mboh, Jikijem, Lang, Kevu and Kesotin have trachytic soils on the fringes of the forest. Trachytic soils are humid with high carbon and organic matter content found in upland Oku at an altitude of $2000 \mathrm{~m}$ and $2600 \mathrm{~m}$. With a slope gradient ranging from $15^{\circ}$ to $40^{\circ}$ [3] the fertility of these areas attracted the population to open farms for the cultivation of basic food crops. Granitic soils are found in northern lowland Oku precisely in Mbam. Rich in quartz and / or mica, these soils are derived principally from granitic parent material dominated by coarse. The soils are well drained, highly permeable and have a high retention capacity. Granitic soils are less humiferous and sandy. They have a deep and fine texture which can easily be eroded. Found in lowland Oku relatively on a flat land area, the rate of erosion is insignificant. At Ibal and Ngemsiba in the South West part of Oku the altitude below 2000m, with pockets of magmatic gneisse. The soils of these two lowlands have a common characteristic in that they receive top soil 
washed from neighbouring high grounds.

\subsection{Vegetation Background}

Part of Oku is occupied by significant remnants of the montane forest with an endangered ecosystem, which is of global importance for conservation. This montane forest has suffered from serious deforestation in search for farm land, fuel, medicine, wood for carving, grazing and many other activities. The search for farm lands is responsible for the rapid deforestation of this montane forest. Forest conservation strategies put in place by the Kilum Mountain Forest Project limits encroachment. Within the past years, intensive agriculture has been carried out in Oku without the possibility of colonizing "new lands". Agro forestry practices therefore favours the planting of specie of trees found in the nearby montane forest such as Prunus africana, Carapa grandiflora, Crassocephalum mannii, Schefflera mannii and many others.

\section{Research Methodology}

\subsection{Research Design}

This research work adopted both primary and secondary methods of data collection in the field. This design was meant to direct the researchers in the use of the best methods of collecting available data. Taking into consideration that the study focused on forest regeneration dynamics and landscape projection, data collection was tailored to ascertain its practice within the study area.

\subsection{Questionnaires Administration}

Primary data was collected using questionnaires. Questionnaire formulated to guide this study were designed in three types namely; structural questions, non structural and semi structural questions.

\subsection{Interviews}

Here, formal and informal interviews were used to gather invisible data. Formal interviews were conducted with resource persons involve directly or indirectly in the planting trees. In all twenty (40) formal and thirty five (35) informal interviews were granted. Data obtained was assembled and then grouped in terms of similar and varied responses in respect to different domains of activity.

\subsection{Forest Visits}

More than seven (07) forest visits were carried out in the locality. The numerous visits carried out permitted the identification of preferable tree species planted, planting techniques, specific trees planted on farms to improve agricultural production, tree maintenance and number of trees planted.

\subsection{Focus Group Discussions}

Common Initiative Group (CIG) discussions on forest maintenance were taken into consideration in the locality. Main attention centered on the need to plant and maintains trees, reduce deforestation and protect forest resources.

\subsection{Data Analysis}

All parameter under investigation were carefully studied and properly analyzed both quantitatively and qualitatively.

\section{Results}

\subsection{Tree Origin and Conservation on Farms as Potentials}

Most farms in Oku have observed several decades of cultivation. The age of the farms cannot really be determined with precision as most of them were inherited from great grandparents. Some of the trees found on these farms equally date several decades back. Some species of tree such as Prunus africana, Carapa grandiflora found in farms adjacent to the Kilum Mountain Forest are remnants of the degraded forest. Their origin and age cannot really be easily determined as they constitute part of the forest of yester years. Some tree species are seasonal such as Tephrosia, vogelli which grow during the rainy season and disappear with the coming of the dry season. During the dry season, this soil fertilizing tree gets dry and is subsequently used as firewood but the fallen seeds stay for a few months and germinate with the coming of the rainy season. It is mostly characterised by its fast spreading nature to nearby farms. This specie of tree is conserved for long on the farm because of its rich fertilizing quality. In a nutshell, Tephrosia vogelli is one of the trees found in a good number of farms. Figure 3 shows the origin of trees found on farms in Oku.

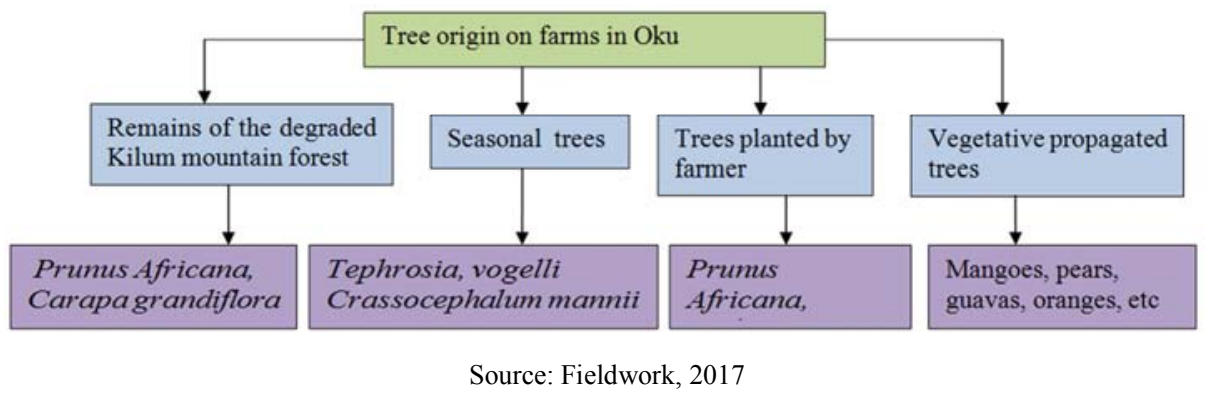

Figure 3. Origin of trees found on farms in Oku.

Another vital tree species found on farms in Oku is Crassocephalum mannii. It is used as a manuring specie. 
Within the study area, it is highly valued for its manure quality on farms. However, besides the natural trees found on farms there are also the artificial or the vegetative propagated species. Most trees found in this category are fruit trees such as mangoes, guavas, pears and oranges to mention just a few. Their propagation is scientifically backed and is geared towards increasing food supply within the study area.

\subsection{A Luxuriant Plant Life Sanctuary as a Base for Forestry Regeneration}

The Kilum Mountain Forest is an excellent example of the high level endemism to be found amongst the flora and fauna of the Cameroon Highlands [4]. The forest supports many birds and plant species unique to the area. The proposed plant life sanctuary covering an area of about 100 hectares is the best example of an intact montane forest. This sanctuary is made up of many habitats such as the upper altitude mountain forest, upland prairie and upland bamboo forest, the lower altitude montane forest, the Gnidia woodland, recolonised scrubland and the montane grasslands. The above areas stand out as the foundation of agro forestry practices in $\mathrm{Oku}$. This is as a result of their immeasurable background for cultivation, livestock rearing and apiary activities.

The upper altitude montane forest is characterised by specie habitat such as Syyzygium staudtii, Xymelos monospora, Repanea melanophloeos, Crassocephalum mannii, Prunus africana and Schefflera abyssinica. Crassocephalum manni and Prunus africana which are the threatened species within this zone. This habitat supports a large population of the Cameroon montane endemic plants [5]. Located within a high altitude forest area, this zone is marked by a cold climatic background. Found at an altitude of more than $2400 \mathrm{~m}$ this zone has a surface area of $40 \mathrm{~km}^{2}$ occupying $17 \%$ of the total land surface of the study area [6]. These areas serve as a habitat for more than $60 \%$ of the total population of livestock found in Oku. Grazing lands rich in pasture for goats, cattle, sheep and horse prevail in this area. Even though considered as an illegal act, livestock farmers still keep large numbers of their flock in this zone. Larger numbers of livestock from this area are a way of diversifying investments. Being an area isolated from houses, livestock found here are bigger in size due to the vast grazing lands available. Research findings from those involved in this practice revealed that $90 \%$ of the farmers visit this area at least once in two weeks.

Slightly below the upper altitude montane forest is the lower altitude montane forest. The characteristic species of the habitat are Syzygium staudtii, Carapa grandiflora, Maesa lancelota, Schefflera mannii and Nuxia congesta. The lower attitude montane forest is an important habitat for Schefflera mannii which is endemic to the Cameroon mountain archipelago. This area is fertile for hives colonised in lowland areas in Oku and then transferred up to this zone. Some of the hives kept here get colonised. With the unique species of trees within the lower altitude forest, the bees get special nectar reflected in the unique quality of the white Oku honey. Trees such as Scefflera mannii and Nuxia congesta adds more to the uniqueness of the honey quality. Upland Oku honey is richer in quality than honey harvested in the low lying areas. Having had international property rights the white Oku honey has gained an international recognition and it is on the international market. In a nutshell, this zone is vital in agro forestry in that of adding value to produce a unique product. The white Oku honey is rich in medicinal values.

The Gnidia glauco woodland is made up of habitat species such as the Schefflera mannii. This zone is covered by montane endemic plants. Located near the upland farms, this zone has suffered enormous deforestation because of the need to acquire farmlands. Most of the forest regeneration process is taking place within this limited area in Oku. This zone at the moment is threatened by the constant search for fuel leading to the felling of trees.

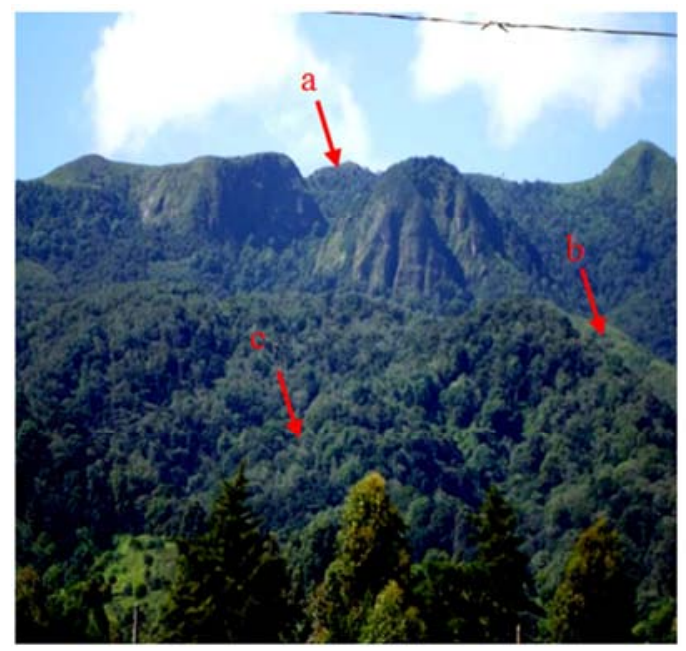

Figure 4. Different vegetation zones of the $K M F$.

a: Upland prairie area

b: Upland bamboo forest

c: Lower altitude montane forest

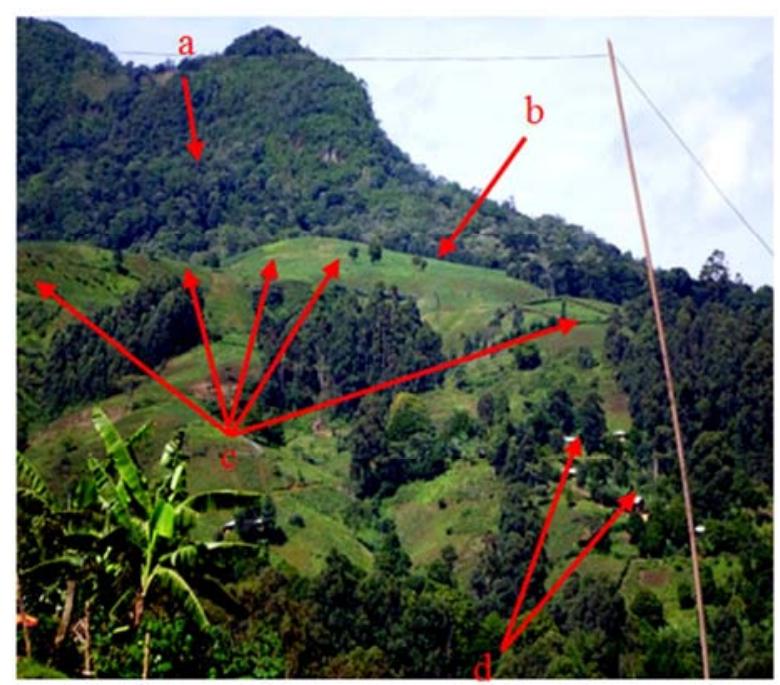

Figure 5. Panoramic view of the landscape of some quarters in Oku.

a: Remaining patch of the montane forest

b: Firm farm forest boundary

c: Deforested areas for farmlands

$\mathrm{d}$ : Houses on areas formerly occupied by farms 
As seen in figure 4, different layers of vegetation are found on the slopes of the Kilum Mountain Forest. The firm farm forest boundary further restricts encroachments into the forest area as seen in the plate above. Buildings have advanced closer to the forest boundary thus reducing areas destined for farming.

\subsection{Enhancing the Delivery of Improved Tree Planting Through Small Scale Nurseries in Rural Areas}

Research results reveal that project intervention trained farmers to set up their private and group nurseries and raise exotic and local species of trees of their choice. Farmers understood the uses of exotic tree species in addition to their indigenous knowledge of the uses of local species.

The project trained 16 farmers selected from all over the study area on the rapid multiplication of trees through vegetative propagation techniques. Such techniques include grafting and marcotting. The project initially set up two nurseries at Mbam and Ibal all in lowland areas. These farms served as training demonstration farms within the area. About 300 marcots were set up by farmers all over the study area on Mangoes, Pears, Guavas, Citrus, Prunus, Canalium and Kolanuts. Within the locality, various tree nursery groups are found and contribute enormously in distributing nursed tree species.

Table 1. Farmers' groups involved in coffee nurseries.

\begin{tabular}{lll}
\hline Name of farmerlorganization & Number of seedlings & Quarters \\
\hline OACU LTD & 23.700 & Keyon \\
Chimtom Solomon Kebuh & 7000 & Manchok \\
Ndikam Victor Kochi & 13.500 & Chieh \\
Itoh Community Grazier CIG & 7000 & Itoh \\
Mbam Modern Farming CIG & 8242 & Mbam Oku \\
Ngwang Andrew Ndifon & 3500 & Lang \\
Tumbong Francis & 4000 & Nang Nkwi \\
Total & 66.940 & \\
\hline
\end{tabular}

Source: SDDARD annual reports

From table 1, improvements in coffee nursery have become a dream come true again in Oku. In 2012, a total number of 66.940 coffee seedlings were nursed all over the research area. Actors involved in this nursery range from groups to individuals [6]. Proximity of individual farmers involved in coffee nursery permits easy distribution throughout the area. Despite the fall in coffee prices in the late 80 's, much re-colonisation of coffee farms is currently going on in Oku. Presently, coffee planting is gaining grounds in most quarters in Oku.

Coffee nursery is encouraged in Oku by the OACU LTD. Every year, seeds are distributed to the farmers specialised in nursery. In return, the farmers put in their individual efforts and jointly distribute the nursed species to other farmers in need of the seedlings. In connection with this, on the $13^{\text {th }}$ of April 2012 on the $14^{\text {th }}$ June 2012 , coffee seeds (Java ${ }^{1}$ ) and 16200 coffee seedlings (Java $\mathrm{F}^{2}$ ) respectively were distributed to the following beneficiaries in Oku as seen in table 2 .
Table 2. Beneficial of Java coffee seedlings.

\begin{tabular}{ll}
\hline Beneficiary & Quantity $(\mathbf{K g})$ \\
\hline OACU LTD & 10 \\
Chimtom Solomon Kebuh & 03 \\
Ndikam Victor Kochi & 05 \\
Itoh Community Grazier CIG & 04 \\
Ngwang Andrew Ndifon & 02 \\
Basilus Tata F. & 01 \\
\hline
\end{tabular}

Source: Fieldwork 26/09/2018

The distribution of these seeds to different farmers is a way of boosting coffee production within the locality. Beneficiary farmers are those exhibiting talents and efforts in nursery practices. Besides java coffee seeds, other farm input also filter down from the union to farmers' groups that have a strong negotiating power.

\subsubsection{Evaluating the Efficiency of Small Scale Coffee Nurseries in Production and Distribution}

As mentioned earlier, coffee is a very important cash crop cultivated in Oku. The trees nursed are sold to farmers when they are ready to be transplanted. The species of trees include coffee seedlings such as Java $\mathrm{F}^{1}$ and $\mathrm{F}^{2}$. Both crop cultivation, pig rearing and coffee nursery is carried on the same piece of land as seen on the photo.

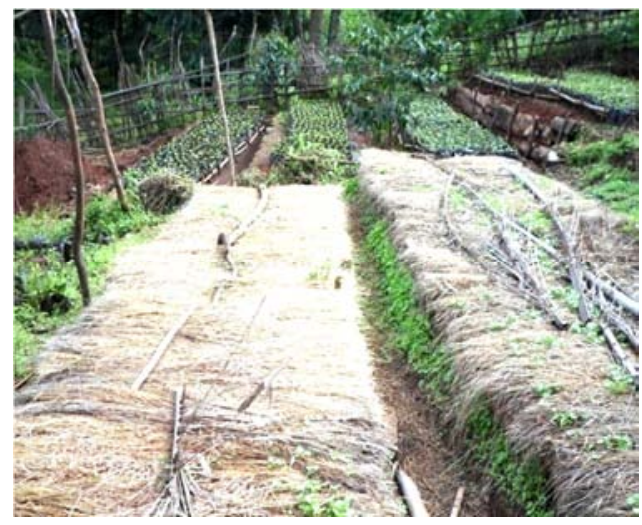

Figure 6. Trees nursery bed in Oku.

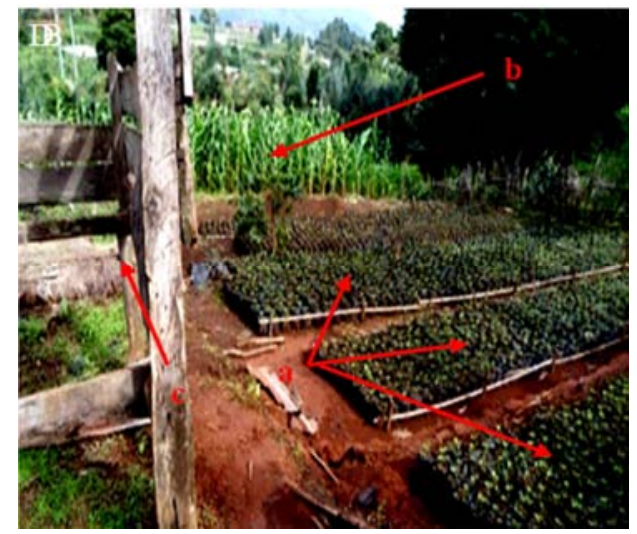

Figure 7. Nursed seeds.

a: Mature nursed coffee in polythene bags ready to be transplanted.

$\mathrm{b}$ : Maize farm within the nursery area.

c: Pig fence

Source: Godwill T. N. 13/07/2019 
As seen in figures 6 and 7, the farmer practices a rotational technique yearly. The soils within the farm is fertilised by the pig droppings in one section of the farm. Every year he rotates the pig fence to fertilise the other areas of the farms. As the pig fence is moved to one end, the soil is gathered and put in polythene bags. Coffee seedlings nursed in a bed are then transplanted and on each polythene bag is fitted one nursed coffee tree [7]. The nursed trees stay for some months before they can be taken for planting. After all this is done, maize is cultivated on the area formerly occupied by the nursed coffee seedlings. Indeed, the farmer maximises his piece of land. The quality and quantity of the maize that is harvested is impressive.

\subsubsection{Growth and Survival of Nursed Coffee Trees in Oku}

The expertise of trained farmers involved in coffee production ensures the growth and survival of this valuable tree. From nursery to transplanting and growth, farmers undergo training on the necessary stages. Strict respect of nursery and transplanting periods is observed by the farmer. With the construction of shelter belts over the nursery, heavy rains from May till July is controlled till when transplanting take place. The cultivation of coffee is basically a male activity while food crop cultivation is designated for the women folk.

Table 3. Grades and quantity of coffee in the Oku Area Cooperative Union.

\begin{tabular}{|c|c|c|c|c|c|c|c|c|}
\hline \multirow{2}{*}{ Year } & \multicolumn{8}{|l|}{ Grades } \\
\hline & A & B & $\mathrm{C}$ & D & $\mathbf{E}$ & $\mathbf{F}$ & $\mathbf{T}$ & Total \\
\hline 2007 & 17.605 & 58.680 & 12.587 & 69.860 & - & 52.837 & 9.120 & $220.689 \mathrm{~kg}$ \\
\hline 2008 & 22.740 & 79.133 & 21.000 & 76.140 & - & 45.180 & 14.142 & $258.335 \mathrm{~kg}$ \\
\hline 2009 & 23.340 & 91.320 & 22.260 & 100.620 & - & 67.920 & 16440 & $321.900 \mathrm{~kg}$ \\
\hline 2010 & 10.860 & 28.260 & 6.000 & 27.360 & - & 17.820 & 54.000 & $113.700 \mathrm{~kg}$ \\
\hline 2011 & 10.560 & 41100 & 9278 & 46140 & - & 34020 & 5412 & $146.510 \mathrm{~kg}$ \\
\hline
\end{tabular}

Source: SDDARD 2015

The presentation of 3 above shows a decrease in coffee harvest in 2010. In 2007, total production of coffee was $220.689 \mathrm{~kg}$. This total moved up to $258.335 \mathrm{~kg}$ in 2008 , $321.900 \mathrm{~kg}$ in 2009 [8]. In 2010, total production dropped to $113.700 \mathrm{~kg}$ and later increased to $146.510 \mathrm{~kg}$. This could be attributed to the simple fact that most coffee farms were cleared during periods of price drop. Attentions were shifted to other productive domains such as livestock and petit trade. At the moment $68 \%$ of farms in lowland areas are being replanted with coffee trees. Maximum production was realized in 2009 with about $321.900 \mathrm{~kg}$. This is attributed to the massive recolonisation of farms and the increase in the number of coffee farmers. In addition, coffee prices equally witnessed a slight increase in kilograms. Coffee during this production year was not really attacked by diseases and the farmers were properly supplied with herbicides and insecticide. In later years, coffee production witnessed a drastic drop to about $146.510 \mathrm{~kg}$. This sub sector needed much assistance form CIG and the OACU LTD [9].

\subsubsection{Domestication and Planting of Fruit Trees}

Trees and shrubs are also domesticated and grown in cropped areas and particularly in compound and far away farms as seen in figure 8 .

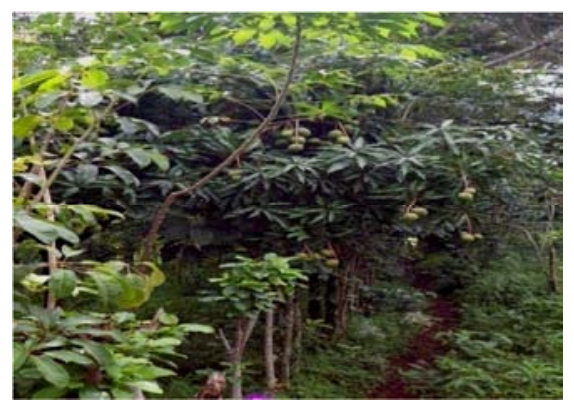

Figure 8. A Mango tree.

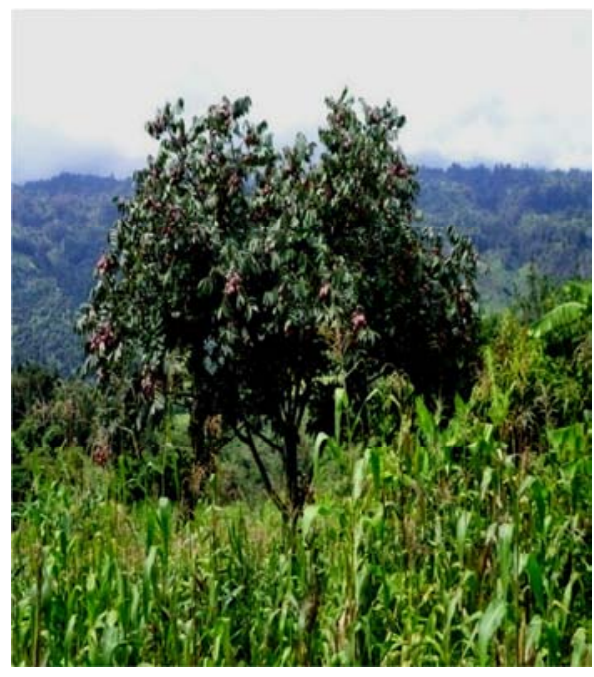

Figure 9. Plum tree.

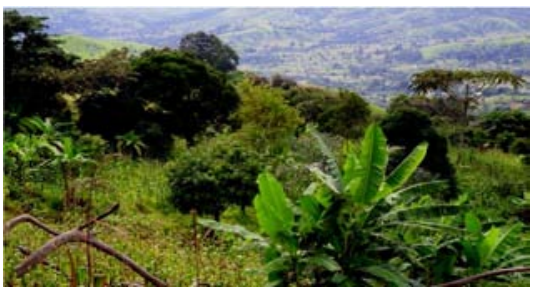

Source: Godwill Tobouah 2019

Figure 10. Panoramic view of trees on the landscape.

Numerous species of trees are grown in Oku as shown in figures 8, 9 and 10. In addition to crops harvested, fruits add significantly to food provision. Some of the popular fruits grown include: mango, avocado, oranges, banana, lemon and grapes as seen in above. Fruit trees are grown on farms and orchards near the homes. These fruit are either consumed or sold to improve family incomes. 


\subsection{Local Perception of Trees in Oku}

Trees constitute an important part within the cultural setting of Oku. The Oku man possesses a particular belief in the special power of trees. This can be seen from the various uses he attaches to tree barks, leaves, roots and fruits from these trees [10]. They are used as food, medicine, for soil fertility improvement, wood carving, decoration and many others.

\subsubsection{Trees used to Maintain Soil Fertility}

Within the study area $95 \%$ of respondent clearly agreed that some specie of trees found on their farms are ways to maintain soil fertility. A good number of these trees such as Tephrosia vogeli, Schefflera abyssinica, Crassocephalum mannili, Leucanea and Gliricardi are found in farms in upland Oku. The leaves and roots of these trees are suitable for maintaining soil fertility.

\subsubsection{Trees to Soften Farms}

Farmers' perception of trees to soften farms varied a lot. About $45 \%$ of farmers interviewed believed that continuous cultivation of their farms was a way of softening the farms while $55 \%$ considered some specie of trees as so good trees for softening of farms. Such trees include Tephrosia vogeli, Schefflera abyssinica and Crassocephalum mannili [11]. Seeds from these species are distributed by wind during the dry season. A good number of these trees are later cut as soon as they start shading their leaves during the dry season. This is a way of signalling that they have attained their maximum productivity and now set for decay. Other trees such as Leucanea and Gliricardi play the vital role of checking wind erosion, building up soil organic matter and recycling nutrients on farms.

\subsubsection{Medicinal Trees}

Oku is renowned for traditional medicine. This has been a long standing practice in the area. The activity has greatly encouraged the cultivation of some tree species used in the preparation of traditional medicine. Trees with rich medicinal value such as Prunus africana, Ricinus communis and Phaseolus vulgaris are found in farms. These brands of trees add more to the mosaic landscape of Oku. Both herbs and trees used as medicine are equally found in shrines and sacred places [12]. The peeling of tree barks such as Prunus africana used in the manufacture of drugs is an illegal act going on in Oku. Through abusive exploitation of Pygaeum barks, Plantecam alone caused 7707 Prunus trees to wither and die in the years 1984 and 1985. In March 1985, 435 Prunus trees were exploited with a total dry weight of $55752 \mathrm{~kg}$ as against 319 trees in May of the same year.

\subsubsection{Trees for Wood Carving}

Trees used for wood carving are spread on farms within the study area. In the past wood carving was one of the lucrative activities employing more than $70 \%$ of youths in $\mathrm{Oku}$ [8]. This was due to the free cutting of trees from the Kilum Mountain Forest. Laws prohibiting the cutting of fresh trees were passed during the Wide Fondom Rules (WFR) of traditional rulers of the forested areas of OKU, Kom and Nso [13]. This pushed carvers to start buying trees found on lands adjacent to the forest as seen in figure 11. With increased scarcity of wood carving trees, carvers now go to distant places to get suitable trees species such as Schefflera and Podocarpus. The involvement of local traditional authorities sanctioned the cutting of fresh trees by carvers. Suitable trees for wood carving such as Schefflera abyssinica and Podocarpos $s p$ are found in farms as seen in figure 11 .

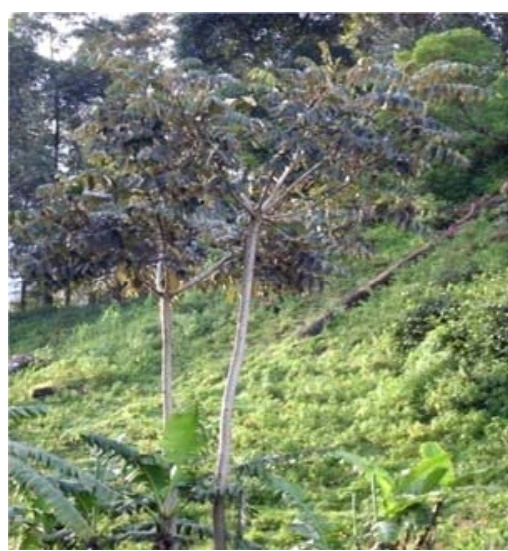

Figure 11. Schefflera abyssinica.

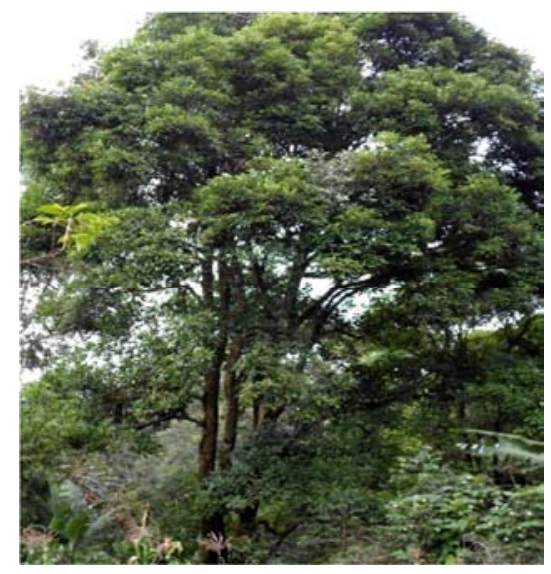

Figure 12. Carapa grandiflora.

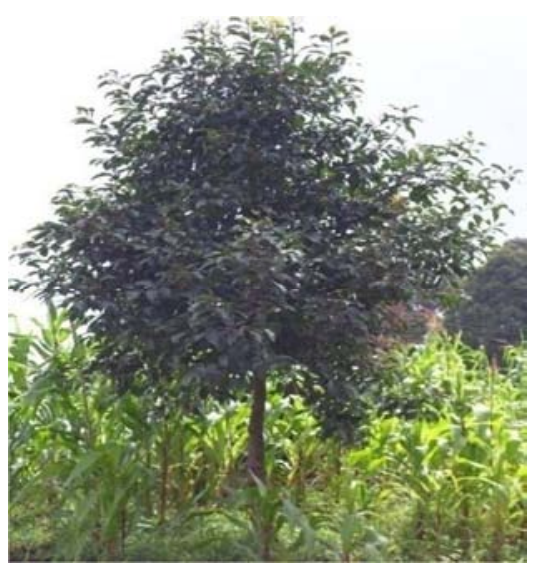

Source: Godwill Tobouah 2019

Figure 13. Prunus Africana 


\subsubsection{Simultaneous Agro Forestry Systems in Oku}

In simultaneous agro forestry systems, the tree and crop components occupy the same land unit at the same time. This system is common in about $80 \%$ of farms in Oku. There is a significant overlap in the growth cycles of tree/crop components. As a result there is direct interaction between the two species that is the tree and the crop species. In simultaneous agro forestry systems, the farmer aims at limiting inter specific competition while in sequential systems, the farmer utilizes the residual effects of the trees. Thus, in shifting cultivation the farmers pile the cut trees into smaller area, burn them and then plant a new crop, which depends on the accumulated ash. In improved fallows, nitrogen fixing trees are deliberately planted to improve soil physical conditions and soil fertility in general, which benefits subsequent crops grown after harvesting the trees [14].

\subsubsection{Sequential Agro Forestry Systems}

Sequential agro forestry systems are those in which trees and crops occupy the same land unit at different times and interaction between them is indirect. The growth of the crop and the tree components occur at different times even when both components may have been planted at the same time. One component species may grow rapidly, while the other grows slowly. Nutrient uptake peaks of the component species may also occur in a sequence, which makes the species complementary in the use of soil resources. Interactions between tree and crop components are reduced with time in sequential agro forestry systems. Examples of sequential agro forestry systems are improved fallows and rotational wood lots. As a matter of fact, this system is not developed in Oku.

\subsection{Improving Rural Livelihoods Through Domestication of Indigenous Fruit Trees}

The systematic diversification from local trees in farms and the introduction of varieties of fruit trees over the years in Oku has greatly improved upon livelihoods. Within this context diversification to fruits trees through local domestication contributes to farm output.

\subsubsection{Supporting Reforestation and Agro Forestry Practices in Oku}

The practice of agro forestry has gained grounds of late in Oku. Tree planting is now common within different groups and institution in present in Oku. Indeed, the natives are conscious of the numerous benefits they get from trees so tree planting is now very common.

\subsubsection{Applying the Seven Billion Tree Campaign at a Local Level in Oku}

Planting of trees to salvage the degrading climate of the earth remains an appeal of international organisations. The United Nations Environment Program (UNEP) and the West Africa Agro Forestry Centre launched the Billion Tree campaign at the climate convention meeting in Nairobi in 2006. Within 18 months; the campaign had encouraged the planting of over 2 billion trees. UNEP executive director Achim Steiner in an interview explained that "having exceeded every target that has been set for the campaign, we are now calling on individuals, communities, business and industry, civil society organisation and government to evolve this initiative on to a new and even higher level". The aim now is to plant 7 billion trees, more than one for every person alive before the crucial climate change conference in Copenhagen in 2009. In contribution to our research on agro forestry, the practice is immensely gaining grounds and promoted at all levels. Drawing inspiration from this, the laudable efforts of the local based NGO is one of the promoters of this campaign. Cameroon Gender and Environment Watch (CAMGEW) launched the planting of 7000 nursed trees in the Kilum forest in January 2012. In this venture, more than 100 community members and leaders participated in tree planting in August 2012 [15]. With support from the administration, the SDO of Oku on the $13^{\text {th }}$ of August launched the tree planting exercise by planting a symbolic tree. The exercise lasted for 15 days and it involved clearing, transportation of seedlings to the forest and planting. From our field investigation we gathered that the natives cherished such exercises. They expressed desires to see it done every year in Oku. Planting trees is one of the most cost effective ways of addressing climate change as trees and forests can absorb carbon dioxide, one of the key greenhouse gases that cause to global warming. The worth of trees in $\mathrm{Oku}$ has gained a primordial place. The domain of agro forestry in Oku remains a striking way in promoting an ever green forest. The natives now see the future of the earth in their hands and are for the vision of properly managing and safe guarding it. In a congratulatory message, the Minister of Environment and Nature's Protection lauded the initiative of CAMGEW. Some ministry staff visited the site where the trees were planted in the forest. The seed of hope is being sown once more in Oku in response to the clarion call for optimism into the future. The impact above can be summarised by the world's Nobel Peace Prize laureate Wangari Marthai and founder of Kenya's Green Belt Movement, "when we plant trees, we plant the seeds of peace and the seeds of hope".

\subsubsection{Domestication of Trees for Home Consumption and the Markets}

The Oku man attaches much value to trees. The importance of trees has resulted in their domestication. Its domestication has gradually gained grounds throughout in Oku. Valuable tree species such as Prunus africana, Dracaena, Schefflera, Calliandra and many others are those from nursery farms. Fruit trees domesticated are the fast maturing specie such as Pears, Guavas, Oranges, Bananas, Citrus, Canalium and Kola nuts. In most cases, the fruits from these trees are destined to be sold in the local markets. Some of the trees such as Scheffflera found on farms are mainly sold to those practicing wood carving. These are suitable trees for wood carving. The prices of these trees range from 4000FCFA to about 6000FCFA and they have a 
ready market once they are big in size. Mostly trees found on farms are considered as a valuable species.

\subsection{Improving Local Livelihoods While Increasing Trees in the Landscape}

Within the study area more than $80 \%$ of the population is involved in agriculture. Through the practice of this activity local livelihood in Oku needs to be improved. Income from the sale of agricultural crops is therefore used in the management of their day to day lives. Money for education, health and for other needs is generated from the sale of these crops. The income realized from this sale will witness a projected increase with the integration of afro forestry products such as fruits, crops and animal products [16]. As a better way of increasing local livelihoods, the numbers of fruit trees in Oku have been increased in farms. Most of the fruit trees are the fast maturing and productive species. Our findings in the field revealed that each household owns a farm with a variety of fruit trees and at times with other variety of trees. The landscape therefore is undergoing an increase in the number of trees thus a better way to improve local livelihoods. The dynamics of this practice has significantly contributes to the land use pattern of Oku. Land use distribution pattern within this rural community is dominated by crop lands, settlement and the area covered by the forest as seen in figure 14 .

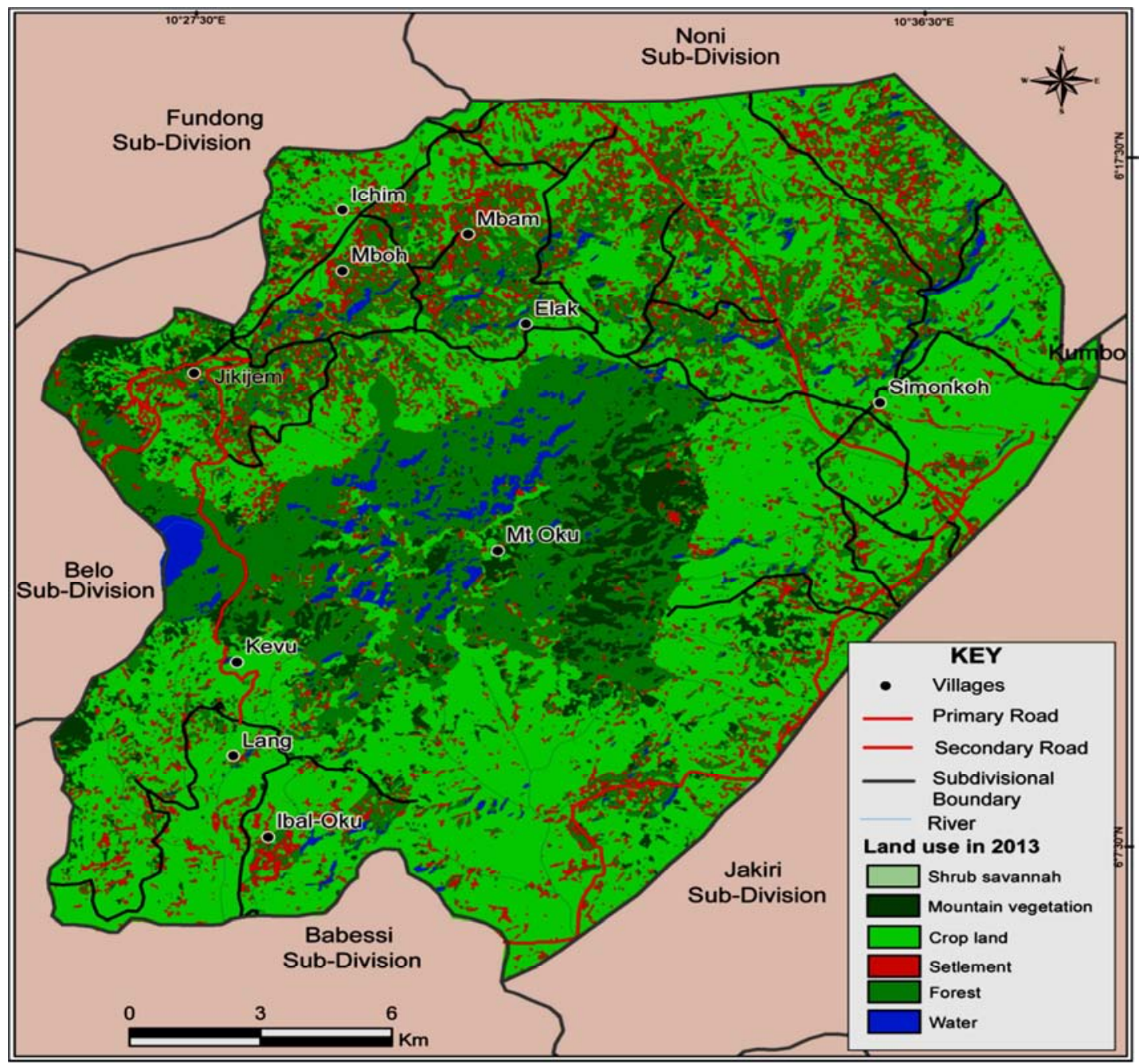

Source: Land sat Image 2019

Figure 14. Land use and occupation of $\mathrm{Oku}$.

\subsection{Mosaic of Tree Planting as a Land Use Patterns on Watershed Function}

Reforestation of the study area supports and protects water shed and quality. The efforts of promoting reforestation in Oku will help regulate water flows and protect valuable sources of water. In recent times, the problem of water scarcity resulting from forest loss is becoming more and more acute. Rural populations in Oku have started to recognize the connection between trees and the quality of water they have access to. This will improve protection and greatly contributes to mitigate the climate change locally and why not regionally. Ornamental trees on their part equally contribute in conserving watershed zones in forest zones in Oku. The pattern of tree distribution on the landscape covers a majority of the area. In Oku during the dry season, a 
majority of streams dry up or simply become mere trickles. This is as a result of recent climatic changes coupled with enormous deforestation that took place with the study area. However, the campaign launched on planting trees is an appropriate measure to combat and protect this watershed zone. Indeed water shed areas needs maximum protection in their vital role of water supply.

\subsection{Landscape Transformation Through Boundary Markings}

Certain multipurpose trees such as Bignoniaceae, Euphorbiaceae, Moraceae and Solanaceae are used to mark farm boundaries in Oku. Unlike live fences, the trees on boundaries need not be closely spaced except in places where soil erosion control is also rampant. Tree growing on farm boundaries requires an agreement between neighbouring farm owners to avoid conflicts. There are different ways of sharing trees planted on a boundary. Sometimes two rows of trees are planted, one on each side of the boundary, and then each farmer grows and manages his own trees. The disadvantage with this is that it occupies more land than a single row. With regard to fieldwork carried out, it shows that initially trees can be established at a close spacing 0.75 $1.00 \mathrm{~m}$ and then later thinned for poles or firewood to a final spacing of $1.5-3.0 \mathrm{~m}$. With double rows, the spacing between the rows should not be less than $2 \mathrm{~m}$. The tree propagation method will depend on the species, but the use of seedlings is common. Grevillea robusta is commonly used for boundary planting in Central Kenya which is a technique that can be properly borrowed and applied in Oku. Its use for this purpose (and also in other agro forestry systems) may be related to its restricted lateral root system. This makes it to associate well with neighbouring crops. In general, trees on boundaries offer several benefits and these together with the limitations of this agro forestry practice contribute in reshaping the landscape.

\subsection{Traditional Live Fences of Trees and Shrubs (Living Fences) Around Farm in Oku}

Live fencing means fences composed of living plants. Living fences are lines of trees or shrubs planted on farm boundaries or on the borders of farmyards, pasture plots or animals enclosures. Sometimes they are also used around agricultural fields. They serve mainly as field boundaries to keep animals on the farm and off adjacent crop fields or farm areas. They can be made of single or multiple densely planted rows. Alternatively, one row of living fence posts can be planted, widely spaced, with wire, sticks or dead branches between the trees. Both kinds are made of permanent lines of shrubs or trees that are regular in distance. The fences provide shade, protection and privacy for the animals. The trees can also serve as windbreaks that produce wood and foliage products. The foliage can be eaten by animals [9]. Legumes are specially valued as they usually have high protein content. The most important component in the living fence practice in Oku is the animal component - the main reason for establishing living fences and the primary motive in management of the fences is to control livestock movement. In arid and semi-arid zones the practice is gradually being developed in most farmlands in Oku. Live fences are often made of thorny species of the Acacia or Prosopis. In the humid and sub - humid tropics, leguminous species such as Gliricidia sepium and Erythrina berteroana or species of multipurpose Hibiscus or Ipomea hedges are used.

\section{Conclusion}

The potentials of trees in Oku remain very vital in forestry development within the locality. Different species of trees now dominates in the Kilum Mountain Forest and on the entire landscape in Oku. This significantly contributes in the protection of the remaining patch of the forest. Findings gathered from this study revealed that the local populations are now conscious about the dangers of deforestation for selfish interest. Moreover, this positive change in mentality spreads benefits on a wider scale. Survey results truely attest to this fact. Based on the findings of this study, it is recommended to promote forest renewal in view of guaranteeing a climatic stable condition in the long run and reap accompanying economic benefits. Local farmers within the study area should be given adequate training on tree planting and appropriate techniques of exploiting forest resources.

\section{Conflict of Interest}

In the course of this work, no conflict of interest was encountered. The authors harmonized their different views in confidentiality to produce an article of relevant quality.

\section{References}

[1] Waugh David, (2002). An integrated Approach, 657 P.

[2] Godwill Tobouah, Moupou Moise, (2019). Perceptions and Reality of Agro Forestry Practices in Oku, Cameroon. Journal of Human Resource Management. Vol. 7, No. 4, 2019, pp. 7886. doi: 10.11648/j.jhrm.20190704.11.

[3] Godwill Tobouah, (2015), Agro Forestry Practices in Oku Sub-Division: An Impetus to Food Supply and Rural landscape Transformation. Masters Dissertation, Department of Geography. University of Yaounde 1. 149P.

[4] Fogwe Zephania N, (1997), Landscape Degradation on the Kom Highlands (North West Province of Cameroon); An Environmental Assessment. Doctorat de $3^{\text {eme }}$ cycle. Department of Geography, University of Yaounde 1, 341P.

[5] Nkwaimbi Wilfred T, (1996), Evolution of Agricultural Zones on Mount Oku, Maitrise Memoir University of Yaoundé I, $120 \mathrm{P}$.

[6] Macleod H, (1987). The Conservation of Oku Mountain Forest. ICPB. Study report $\mathrm{N}^{\circ} 15$ Cambridge. 
[7] Cheek M., Gosling G., Pollard B., and Pato A., J., (1998), Checklist of the flora of Mount Oku. Working document RBG Kew.

[8] Forbosel P., and Maisels (1999), Habitat Preferences of Common Montane.

[9] Enchaw Gabriel B., (2004), Major Conservation Strategies Adopted for the Sustainable Management of Natural Resources in the Kilum-Ijim Forest Project Area, N. W. P of Cameroon, DEA in Geography, University of Yaoundé 1, 93P.

[10] Yengo Genesis T., (1998). Wood carving in Oku: An Economic Activity in Expansion DIPES II Dissertation ENS Yaoundé 1, 130P.

[11] CAMGEW (2012) Report: Success Story.

[12] Hawkins R., and Brunt, (1965), The Soils and Ecology of West Cameroon, Volume 1, FAO, Rome, 212P.
[13] Godwill Tobouah, Nchamcham Olive (2019). Common Initiative Groups (CIGs) Enhancement in Agricultural Production Oku, Cameroon. International Journal of Sustainable Development Research. Vol. 5, No. 3, 2019, pp. 71-78. doi: 10.11648/j.ijsdr.20190503.12.

[14] Godwill Tobouah, (2019). Productivity Challenge of Soils Along the Slopes of Mount Oku in Cameroon. Fluid Mechanics. Vol. 5, No. 1, 2019, pp. 1-7. doi: 10.11648/j.fm.20190501.11.

[15] Ojuku T., (2005), Dynamics and Impacts of Vegetable Cash Income Population Movement in the Bamboutous Highlands of Cameroon from 1960 - Present. Ph. D Thesis Department of Geography. University of Yaoundé 1.

[16] Nchamcham Nsungnen O., (2015), The Contribution Of Common Initiative Groups To Agricultural Production In Oku Sub-Division, University of Bamenda 91. 